\title{
XV KONFERENCIJA YU INFO 2009
}

Potpukovnik mr Nebojša Gaćeša, dipl. inž., nebojsa.gacesa@mod.gov.rs, Uprava za školstvo, Sektor za ljudske resurse MO

Na Kopaoniku je od 8. do 11. marta 2009. godine održana XV jubilarna međunarodna konferencija iz oblasti infomacionih i komunikacionih tehnologija (ICT) - YU INFO 2009.

Konferencija je održana pod okriljem Informacionog društva Srbije udruženja za informacione sisteme i računarske mreže. To je neprofitna i nevladina organizacija koju čine stručnjaci iz računarskih i telekomunikacionih oblasti, kao i predstavnici vodećih domaćih IT kompanija. Bavi se popularizacijom savremenih tehnologija, širenjem informacija iz ove oblasti, organizovanjem simpozijuma, konferencija i različitih načina obuke, kao i učešćem na projektima koji se bave IT problematikom. Članovi društva su IT eksperti iz poslovnih, akademskih i naučnih krugova, kao i stručnjaci iz sektora državne uprave. Glavne aktivnosti ovog udruženja su, pre svega, povezane sa organizovanjem konferencija i seminara, od kojih je najznačajnija YU INFO konferencija.

Ovogodišnja Konferencija YU INFO okupila je preko 400 ICT profesionalaca, istraživača i menadžera iz zemlje i regiona, koji su imali priliku da se upoznaju sa najnovijim trendovima, projektima i rešenjima u oblastima ICT i da se povežu u međunarodnu mrežu ICT eksperata.

Ova konferencija već godinama omogućuje svojim učesnicima da, kroz raznovrsne programske forme, čuju iskustva najboljih i prošire svoju mrežu poslovnih kontakta.

Ove godine, pored Konferencije i kompanijskih prezentacija rešenja, na programu su bile i dve panel diskusije: panel diskusija ICT lidera iz Srbije i panel diskusija o mogućnostima i izazovima učestvovanja na EU projektima.

Programski i organizacioni odbor XV konferencije YU INFO 2009 sačinjavalo je 30 profesora sa Elektrotehničkog fakulteta Beograd, Fakulteta organizacionih nauka Beograd, Fakulteta tehničkih nauka Novi Sad, Prirodnomatematičkog fakulteta Novi Sad, Elektronskog fakulteta Niš, Tehničkog fakulteta Zrenjanin, Florida Atlantic University-a iz SAD, Megatrend Univerziteta Beograd, FIT Beograd, SF Beograd, Ekonomskog fakulteta Skoplje, Faculty of Electrical Engineering Ljubljana, kao i predstavnici Informacionog društva Srbije.

Sesije i panel diskusije XV konferencije YU INFO 2009 obuhvatale su sledeće programske oblasti:

- e-Society (e-Learning, e-Government, e-Business, e-Health, Internet ...),

- Informacioni sistemi,

- Razvoj softvera i alati, 
- Veštačka inteligencija i računarska simulacija (ekspertni sistemi, sistemi za podršku odlučivanju ...),

- Računarske mreže i telekomunikacije,

- Računarski hardver i sistemi,

- Primenjena informatika (proizvodnja, mašinstvo, elektrotehnika, građevinarstvo, poljoprivreda ...),

- Zaštita podataka i pravni aspekti.

U radnom delu konferencije, u okviru 12 sesija i četiri postera, izložena su 174 rada (u okviru sesija 87 radova - na konferenciji oko $75 \%$ radova i 96 radova na panelima, uz prisustvo oko $60 \%$ autora ili koautora). Radovi su izazvali značajno interesovanje, a prisustvo velikog broja mladih autora pokazuje da ova konferencija ima dobru perspektivu.

Bogat radni i društveni program doprineo je celokupnom utisku proslave jubileja, a učesnicima su bile na raspolaganju brojne teme i programske forme (prezentacije autorskih radova, kompanijski nastupi, panel diskusije i prateći program).

Predavanja po pozivu u okviru sesije otvaranja konferencije, odnosila su se i na stručnu javnost i na menadžment kompanija. Tako je Dejan Cvetković iz Microsofta održao prezentaciju o „Timovima i liderima: kako zajedno do cilja“, uporedivši liderstvo sa tipičnim poimanjem menadžmenta.

Prof. dr Sašo Tomažič sa Univerziteta u Ljubljani je govorio o „Kvalitetu života u informacionom društvu“, analizirajući odgovor na pitanje ima li kvaliteta života (posle) IT?

Dr Srđan Krčo iz Ericssona-Irska održao je predavanje na temu „Integration of the Physical and Digital World in the Network of the Future SENSEI point of view“, o Sensei projektu i senzorskim mrežama kao budućnosti umrežavanja.

Prvog radnog dana predavanje po pozivu održao je i prof. dr Nikola Šerbedžija, sa instituta Fraunhofer FIRST na temu „Mixed Feelings Systems“.

Kako jednom jubileju i priliči, dodeljene su nagrade za izuzetan doprinos radu Konferencije YU INFO tokom proteklih 15 godina, sledećim istaknutim učesnicima i organizatorima:

- prof. dr Branimiru Đorđeviću, Univerzitet u Nišu,

- prof. dr Jelici Protić, prodekanu Elektrotehničkog fakulteta u Beogradu, hroničaru konferencije,

- prof. dr Zori Konjović, Fakultet tehničkih nauka u Novom Sadu,

- Igoru Pavlici, Saga d. o.o. Beograd,

- mr Dušanu Korunoviću, Deux ex Machina.

Na konferenciji je učestvovalo 14 kompanija čije su prezentacije i nagradne igre privukle pažnju brojnih učesnika, među ostalim Comtrade, IBM, King ICT, ENEL PS, Saga d. o.o, Telekom Srbija... 


\title{
Pregled radova pripadnika Vojske Srbije i Ministarstva odbrane Republike Srbije po sesijama
}

\author{
Sesija S 1.1 \\ Programska oblast E-SOCIETY (E-Learning) \\ Goran Šimić, Vojna akademija Beograd,
}

Aleksandar Jevremović, Univerzitet Singidunum Beograd

CASE STUDIES IN PROBLEM BASED LEARNING

$U$ radu su predstavljene dve aplikacije učenja rešavanjem problema (PBL - problem based learning): PBL u Java programiranju i PBL u računarskim mrežama. PBL predstavlja pedagošku strategiju usmerenu na studente u kojoj oni uče kroz iskustva stečena u rešavaju konkretnih problema i zadataka. Različiti domeni korišćenja ovih sistema (npr. matematika, medicina, umrežavanje računara, programiranje) zahtevaju različite pristupe u njihovom dizajnu. Zbog toga su predstavljene dve studije slučaja korišćenja. Obe aplikacije razvijene su kao dodatni moduli za postojeći sistem za upravljanje učenjem (LMS - learning management system). Na taj način dobija se dvostruka korist: proširuje se osnova funkcionalnosti LMS i resursi učenja koji postoje u LMS, a mogu da budu korišćeni u PBL modulima.

Ivan Tot, Vojna akademija Beograd

INFORMACIONA PODRŠKA POSLOVIMA SMEROVA NA VOJNOJ AKADEMIJI

$\mathrm{U}$ ovom projektu predstavljen je primer automatizacije procesa koji se odnose na funkcionisanje smera na Odseku logistike u Vojnoj akademiji. To u organizacionom smislu podrazumeva analizu ispitnih rokova $i$ vođenje evidencije o ispitima studenata, praćenju brojnog stanja studenata, vođenju rednih listi, itd.

\section{Sesija S 4.1}

Programska oblast VEŠTAČKA INTELIGENCIJA

Boban Bondžulić, Vojna akademija Beograd, Dimitrije Bujaković, Vojna akademija Beograd,

Vladimir Petrović, Imaging Science - University of Manchester SJEDINJAVANJE MULTIFOKUSIRANIH SLIKA

$U$ ovom radu opisane su neke od tehnika sjedinjavanja multifokusiranih slika kod kojih se sjedinjena slika dobija preuzimanjem blokova izvornih slika koji u sebi nose više informacija. Rezultati sjedinjavanja opisanih tehnika upoređeni su sa rezultatima sjedinjavanja pikselnih tehnika. 
Za procenu rezultata sjedinjavanja korišćene su objektivne mere procene. Naime, scena koju je potrebno snimiti obično sadrži objekte na različitim udaljenostima od kamere. Oštrina slike ovakve scene zavisi od različitih faktora. Objekti koji se nalaze u fokusu su jasniji, dok jasnoća objekata koji se nalaze ispred i iza fokusirane distance postepeno opada. Sjedinjavanjem slika sa različitim podešavanjima fokusa može se dobiti slika kod koje su svi objekti u fokusu.

Sesija S 4.2 lacija...)

Programska oblast VEŠTAČKA INTELIGENCIJA (Računarska simu-

Dimitrije Bujaković, Vojna akademija Beograd,

Boban Bondžulić, Vojna akademija Beograd,

Mladen Antonić, Vojna akademija Beograd

JEDAN PRISTUP ANALIZI UTICAJA KOLOR KOORDINATA NA MOGUĆNOSTI PRAĆENJA OBJEKATA

$U$ radu je opisan jedan od metoda za detekciju i praćenje objekata na slici scene. Korišćena je pseudorealna sekvenca kolor slika. Izvršena je analiza uticaja primenjenih kolor koordinata na mogućnosti detekcije i praćenja objekata u realnoj sekvenci. Mera kvaliteta detekcije je greška detekcije u svakom frejmu sekvence. Pokazano je da kvalitet detekcije zavisi od primenjene kolor koordinate i da je korišćenjem pojedinih kolor koordinata nemoguće izvršiti detekciju i praćenje objekta u realnoj sekvenci

\section{Sesija S 5.2}

Programska oblast RAČUNARSKE MREŽE I TELEKOMUNIKACIJE

Milenko Andrić, Vojna akademija Beograd,

Stojadin Manojlović, Vojna akademija Beograd

ANALIZA RADARSKIH SIGNALA POMOĆU SPEKTRALNE ENTROPIJE

Ovaj rad predstavlja razmatranje spektralne entropije, korišćene za detekciju zvučne aktivnosti, u kontekstu detekcije radarskog signala. Sprovedena je analiza audio Doplerovog signala na bazi rezultata dobijenih pomoću spektralne entropije. Maksimalna Doplerova frekvencija signala je $2 \mathrm{KHz}$. Entropija ima važnu osobinu da je nezavisna od apsolutnog skaliranja kako po amplitudi tako i po frekvenciji signala. Prisustvo radarskog cilja koji se kreće u procesu radarskog osmatranja uzrokuje zvučne komponente u audio Doplerovom signalu koje operator može da čuje. Povećavanje subjektivnog osećaja o čistoći audio Doplerovog signala uzrokuje smanjivanje vrednosti spektralne entropije. Zato se spektralna entropija može koristiti kao važno obeležje u procesu detekcije radarskog signala. 
Poster sesija P1

Programska oblast E-SOCIETY (E-Learning, E-Goverment, E-Business, E-Health, Internet...)

Željko Mihić, Vojna akademija - Odsek logistike, Beograd,

Đuro Alfirević, Ministarstvo odbrane Republike Srbije, Beograd,

Uroš Racković, Generalštab Vojske Srbije, Beograd

TESTIRANJE STUDENATA NA VOJNOJ AKADEMIJI PRIMENOM SOFTVERSKOG PAKETA I WEB APLIKACIJE

Ovaj projekat predstavlja praktičnu realizaciju jednog informacionog sistema koji će omogućiti automatizaciju procesa testiranja studenata upotrebom računara i lokalne računarske mreže primenom Web aplikacije.

Zoran Gavranović, Ministarstvo odbrane Republike Srbije, Beograd,

Nikola Simić, Ministarstvo odbrane Republike Srbije, Beograd

E-REGRUTOVANJE U PROCESU PRIBAVLJANJA LJUDSKIH RESURSA

Uspešno regrutovanje u procesu pribavljanja ljudskih resursa počiva na sposobnosti da se lociraju adekvatni kandidati i pozicije za talentovane pojedince $u$ organizaciji i van nje. E-regrutovanje nudi nove mogućnost podrške za menadžment ljudskih resursa i čini organizaciju konkurentnijom na tržištu rada.

Poster sesija P2

Programske oblasti INFORMACIONI SISTEMI • RAZVOJ SOFTVERA I ALATI

Branko Jovanović, Vojna akademija Beograd,

Marko Papović, Vojna akademija Beograd

INFORMACIONI SISTEM KATEDRE ZA FIZIČKU KULTURU VOJNE AKADEMIJE

Ovaj rad predstavlja predlog da se posao Katedre za fizičku kulturu Vojne akademije, koji se odnosi na praćenje rada studenata ocenjivanjem fizičke sposobnosti, obavi efikasnije i lakše.

Marko Ristić, Vojna akademija Beograd,

Marko Dragonjić, Vojna akademija Beograd

INFORMACIONI SISTEM STOMATOLOŠKE ORDINACIJE NA VOJNOJ AKADEMIJI

Na Vojnoj Akademiji nalazi se ambulanta sa stomatološkom ordinacijom. Kao i u ostalim ustanovama koje se bave stomatologijom, neophodno je da se vodi detaljna i sveobuhvatna evidencija o pacijentima vojnim licima, kao i svakom tretmanu koji je ikada rađen za svako vojno lice u garnizonu. Vođenje evidencije takvog tipa na sadašnji način je za- 
starelo i zahtevno. Zato je potreban savremeni informacioni sistem koji bi ubrzao proces evidentiranja, olakšao čuvanje podataka o pacijentima, kao i prebacivanje kartona pacijenata u ordinacije u drugim garnizonima. Ovaj rad nudi takvo rešenje.

Marko Papović, Vojna akademija Beograd,

Branko Jovanović, Vojna akademija Beograd

INFORMACIONI SISTEM ZA EVIDENCIJU KVAROVA MATERIJALNO TEHNIČKIH SREDSTAVA VOJSKE SRBIJE

$\mathrm{Na}$ Vojnoj akademiji evidenciju i prijavljivanje kvarova materijalnotehničkih sredstava obavlja referent čete ručno, što je prilično neefikasan način s obzirom na brzinu unošenja i preglednost evidencije. Ovaj rad je pokušaj da se taj postupak automatizuje i da se poboljša kontrola upotrebe materijalno-tehničkih sredstava.

Komlen Lalović, Vojna akademija Beograd,

Slađan Milošević, Elektrotehnički fakultet Beograd

INFORMACIONI SISTEM AEROFOTO SNIMANJA ZA POTREBE VOJSKE SRBIJE

Ovaj rad opisuje informacioni sistem koji se bavi tematikom aerofoto snimanja zemljanih površina, objašnjava njegovu zamisao, namenu i sam način funkcionisanja.

Nenad Tomić, Vojna akademija Beograd,

INFORMACIONI SISTEM ZA IZRADU PLANA POLAGANJA ISPITA NA VOJNOJ AKADEMIJI

$\mathrm{Na}$ Vojnoj akademiji izrada plana polaganja ispita do sada se obavljala ručno, pri čemu je često dolazilo do grešaka pri unosu, što je otežavalo rad profesorima, studentima i referentima koji su zaduženi za planiranje i organizaciju izrade plana polaganja ispita. Radi bolje funkcionalnosti plana polaganja ispita javlja se potreba za informacionim sistemom koji će omogućiti olakšano unošenje podataka o ispitnom roku (naziv ispitnog roka, školska godina) i ispitnim obavezama (predmet, nastavna grupa, profesor, prostorija, itd). Ovaj rad nudi takvo rešenje.

Marko Dragonjić, Vojna akademija Beograd,

Marko Ristić, Vojna akademija Beograd

ANALIZA ISPITNIH ROKOVA NA NIVOU ČETE 1. STUDENTSKOG PUKA VOJNE AKADEMIJE

Vojna akademija (VA) u Beogradu predstavlja visokoškolsku ustanovu u sistemu obrazovanja Ministarstva odbrane i kao takva na njoj se školuje veći broj, kako budućih oficira, tako i deo trenutnog profesionalnog sastava Vojske Srbije. Kod studenata koji se školuju za poziv oficira, ovaj veliki broj polaznika je utoliko kompleksniji, jer se ogleda u spektru različitih smerova i specijalnosti koje postoje u 1. studentskom puku VA. Zbog različitih nastavnih 
grupa i velikog broja različitih nastavnih planova i programa, sve analize ispitnih rokova su otežane. Ovaj program pokušava da olakša posao komandirima četa tako što će izvršiti automatizaciju samog procesa obrade podataka.

Poster sesija P3

Programske oblasti

VESTAČKA INTELIGENCIJA (Veštačka inteligencija, Računarska simulacija, Sistemi za podršku odlučivanju, Ekspertni sistemi)

RAČUNARSKE MREŽE I TELEKOMUNIKACIJE - KOMPONENTE, SISTEMI I INŽENJERING

Komlen Lalović, Vojska Srbije,

Ivan Jovanović, Vojska Srbije,

Iva Gruić, Elektrotehnički fakultet, Beograd

UVOD U PRETRAGU PODATAKA POSLOVNIH PROCESA

$U$ ovom radu analizirana je „pretraga podataka“ u smislu „pametne pretrage“, pojam „pretraga“, način upotrebe „pogleda na ono što treba da uradimo“ radi dobijanja „poslovne inteligencije“. Takođe, prikazano je sedam algoritama pretrage koji se nalaze u MS SQL Server 2005 i pokazano za šta je svaki od njih optimalan.

Boban Pavlović, Vojna akademija Beograd,

Milojko Jevtović, Jugoslovenska inženjerska akademija u Beogradu

ANALIZA KARAKTERISTIKA SIGNALIZACIONIH PROTOKOLA PAKETSKIH MREŽA

$U$ radu su prikazane osnovne karakteristike, prednosti i nedostaci signalizacionih protokola paketskih mreža. Takođe, ukazano je na mogućnosti njihovog međusobnog povezivanja radi obezbeđenja prenosa preko heterogenih mreža.

Vladimir Petošević, Vojna Akademija Beograd

VRSTE VIDEOKONFERENCIJE I KONTROLA TOKA

Kontrola toka videokonferencije nameće podelu na nekoliko glavnih vrsta koje u osnovi određuju način konekcije, rada i razmene sadržaja:

- point-to-point i multipoint videokonferencija podrazumeva povezanost dve ili više konferencijskih tačaka u simultanu interakciju. Pored obaveznog CODEC uređaja u slučaju multipoint veze neophodna je i MCU (Multipoint Control Unit) jedinica;

- glasovno uključivanje u konferenciju se podrazumeva za multipoint konferenciju i podrazumeva da zvučni signal obezbeđuje prisustnost u komunikaciji. Kontrola predsedavajućeg mu daje mogućnast odabira prihvatanja i prikaza slike, dok svi saitovi prihvataju sav zvuk;

- kontinualno prisustvo podrazumeva konstantnu uključenost svih sajtova zvukom i slikom.

Poster sesija P4

Programska oblast PRIMENJENA INFORMATIKA (proizvodnja, mašinstvo, elektrotehnika, građevinarstvo, poljoprivreda ....) 
Ivan Vulić, Generalštab Vojske Srbije

PRIMENA INTELIGENTNIH MOBILNIH KLIJENATA U INTERVENTNIM GEOGRAFSKIM INFORMACIONIM SISTEMA

Interventni geografski sistemi predstavljaju specijalizaciju klase mobilnih geografskih sistema koja podržava potrebe donosioca odluka u interventnim situacijama. Interventne situacije zahtevaju pristup prostornim podacima u realnom vremenu. $U$ radu je prikazana mogućnost primene inteligentnih mobilnih klijenata radi zadovoljenja potreba korisnika interventnih geografskih sistema za vremensko-prostornim podacima u realnom vremenu u ograničenom komunikacionom okruženju.

Aleksandar Stanojević, Vojna akademija Beograd

OBJEKTNOORIJENTISANI RAZVOJ SISTEMA ZA VOĐENJE EVIDENCIJE USPEHA UČENIKA VOJNE GIMNAZIJE

Vođenje evidencije o uspehu učenika Vojne gimnazije zahteva mnogo truda i vremena. Postoje pokušaji da se taj proces pojednostavi i automatizuje, što se, međutim, nije pokazalo dovoljno efikasnim. Ovaj projekat treba da omogući korisniku u mrežnom okruženju što efikasniji pristup informacijama.

Stojadin Manojlović, Vojna akademija Beograd,

Stevica Graovac, Elektrotehnički fakultet Beograd,

Milenko Andrić, Vojna akademija Beograd

PRIMENA ADAPTIVNOG UPRAVLJANJA U SINTEZI AUTOPILOTA KOD RAKETA MALOG DOMETA

$U$ radu je analizirana primena dva tipa adaptivnog upravljanja u sintezi autopilota: autopilot sa gain-scheduling adaptacijom parametara i autopilot sa samopodešavanjem. Kao objekat upravljanja posmatrana je hipotetička samovođena raketa malog dometa. U programskom paketu SIMULINK formirani su simulacioni modeli kretanja rakete u scenarijima gađanja nemanevrišućeg i manevrišućeg cilja u dolasku i odlasku.

Davorin Mikluc, Vojna akademija Beograd,

Željko Đurović, Elektrotehnički fakultet Beograd

KOMPARATIVNA ANALIZA ALGORITAMA ZA PRIDRUŽIVANJE PODATAKA U SISTEMIMA ZA PRAĆENJE VIŠE POKRETNIH CILJEVA

U ovom radu je predstavljena komparativna analiza 9 algoritama za pridruživanje podataka. Usvojeni kriterijum za poređenje algoritama za pridruživanje podataka je odnos broja potvrđenih i broja formiranih tragova u sistemu za praćenje više pokretnih ciljeva. Algoritmi su primenjeni na scenariju sa tri pokretna cilja, koja vrše jedan manevar.

$\mathrm{Na}$ XV konferenciji YU INFO 2009, kao uostalom i prethodnih godina, ističe se učešće pripadnika Vojske Srbije i Ministarstva odbrane Republike Srbije. Takođe, zapaženo je i značajno prisustvo radova mlađih učesnika - studenata Vojne akademije.

Dopunski izvori

[1] Zvanična internet prezentacija Informacionog društva Srbije, www.edrustvo.org. 27. 4. 2009. 